\title{
Values and Hostile Intent Attribution to Out-Groups within China-Japan Relations: The Mediating Role of Perceived Threats
}

\author{
LiHua Huang ${ }^{1}$, Kengo Nawata ${ }^{2}$, Takeru Miyajima ${ }^{1} \&$ Hiroyuki Yamaguchi ${ }^{3}$ \\ ${ }^{1}$ Graduate School of Human-Environment Studies, Kyushu University, Kyushu, Japan \\ ${ }^{2}$ Institute of Decision Science for a Sustainable Society, Kyushu University, Kyushu, Japan \\ ${ }^{3}$ Faculty of Human-Environment Studies, Kyushu University, Kyushu, Japan \\ Correspondence: LiHua Huang, Graduate School of Human-Environment Relations, Kyushu University, 6-10-1, \\ Hakozaki, Higashi-ku, Fukuoka 8128581, Japan. Tel: 81-90-8289-9343. E-mail: reikahuang@gmail.com
}

Received: July 3, 2015 Accepted: July 17, 2015 Online Published: August 12, 2015

doi:10.5539/ijps.v7n3p97 URL: http://dx.doi.org/10.5539/ijps.v7n3p97

This work was supported by JSPS KAKENHI Grant Number 26285145.

\begin{abstract}
This study examines a specific effect of hostile intent attribution within intergroup relationships. Based on our application of integrated threat theory, we hypothesised that different types of symbolic and realistic threats had a mediating effect on relations between basic human values (traditionalism and universalism) and hostile intent attribution. We conducted a survey among two university population samples of Chinese and Japanese respondents. The results for our first sample of Chinese undergraduate students $(N=201)$ revealed that both traditionalism and universalism predicted hostile intent attribution and that these relations were fully mediated by symbolic threats, but not by realistic threats. However, the results for the second sample of Japanese undergraduate students $(N=256)$ differed, indicating that traditionalism, but not universalism, predicted hostile intent attribution, and that this relation was fully mediated by both symbolic and realistic threats. In conclusion, we discuss the theoretical and practical implications of these findings.
\end{abstract}

Keywords: hostile intent attribution, traditionalism, universalism, realistic threats, symbolic threats

\section{Introduction}

\subsection{Conceptions of China-Japan Relations within Social Psychological Studies}

China and Japan enjoy very close cultural and economic relations that stretch back to antiquity. Currently, China is Japan's largest trading partner (Nishimura \& Hirayama, 2013), while Japan is also one of China's most important economic partners (Dean, Lovely, \& Mora, 2009). Yet, despite the critical importance of the cooperative partnership between these two nations, relations between their respective populations are strained because of contrasting viewpoints relating to the Second World War and associated political problems that remain unresolved (Qiu, 2006; He, 2007). For example, in 2012, striking and widespread anti-Japan demonstrations occurred in response to the Japanese government's nationalisation of the Diaoyu Islands (known as the Senkaku Islands in Japan) (Nye, 2013). These events signalled a climax in the deteriorating relationship between these two nations. According to reports published by the China Daily and by The Genron NPO of Japan, about 64.5 and 84 per cent of the Chinese and Japanese populations, respectively, harbour negative impressions of each other (Koh, 2012). In this study, we analysed the relationship between China and Japan from a socio-psychological perspective.

\subsection{Hostile Intent Attribution in Intergroup Relations}

The current study focuses on a specific aspect of the attribution of a hostile intent to out-groups in relations between China and Japan. Hostile attribution bias occurs in ambiguous situations wherein people interpret the intent of others as hostile in accordance with their expectations (Milich \& Dodge, 1984). Hostile intent attribution can be viewed as a kind of cognitive bias, or a general schema that leads to an understanding of social events from a perspective of hostility (Dill, Anderson, \& Deuser, 1997; Spector \& Fox, 2010). For example long-term rivalry between China and Japan has caused confusion in relation to people's assessments of who is 
the perpetrator and who is the victim. In this situation, in-group members may be inclined to see each other as hostile to maintain positive feelings towards the in-group. Hostile intent attribution to out-groups (the subjective experience of hostility) is a kind of prejudice, indicating that in-group members perceive a malicious intention to harm the in-group on the part of the out-group. It is clear from the interpersonal literature that there is an association between hostile intent attribution and aggression (Matthews \& Norris, 2002; Tremblay \& Belchevski, 2004). However, few studies have examined the influence of hostile intent attribution within an intergroup context. A demonstrated function of hostile intent attribution is to motivate aggression (Tremblay \& Belchevski, 2004), resulting in aggression-inducing cognition (Spector \& Fox, 2010). Consequently, it has been argued that hostile intent attribution would be likely to operate in public decision making, thereby increasing public support for aggressive policies towards out-groups. Thus, this study considered hostile intent attribution as a key factor in examining its influence on intergroup relations.

The core focus of our study is an exploration of the relationship between basic human values and hostile intent attribution. Furthermore, we identified the psychological processes underlying the effects of traditionalism and universalism on hostile intent attribution that are mediated by perceived threats. In this paper, we first review theories of hostile intent attribution, traditionalism, universalism and perceived threats. Based on this theoretical review, we develop hypotheses on the relationship between basic human values and hostile intent attribution. We then test our hypotheses using the results of surveys conducted in China and Japan. In the final section of the paper, based on our statistical analysis and discussion of the survey results, we examine the study's implications and propose a future research agenda.

\subsection{Values as Antecedents of Hostile Intent Attribution}

Values are criteria or standards that guide people in selecting and justifying their actions, as well as in evaluating people or events (Schwartz, 1992). Individual attitudes and behaviour are associated with these values. A study by Halperin and Bar-Tal (2011) has shown that the value of traditionalism is associated with the avoidance of intergroup compromise, while the value of universalism entails the promotion of positive intergroup relations. We consider values that have been long ignored to be important factors in relation to intergroup conflicts. Thus, an investigation of the effect of values on intergroup conflicts is pertinent.

Schwartz (1992) has identified ten types of basic values relating to people's motivation. In the current study, we opted to examine the relationship of two of these values, namely, traditionalism and universalism, with hostile intent attribution for the following reasons. First, traditionalism has been found to be associated with negative attitudes towards out-groups (Schwartz, 2006a; Halperin \& Bar-Tal, 2011). Second, compared with other values (for example, benevolence), universalism is more likely to promote acceptance of out-groups (Schwartz, 2007) and positive intergroup relations. We, therefore, selected traditionalism and universalism as the two antecedent variables in our study.

\subsubsection{Traditionalism}

Traditionalism entails an attitude of respect, commitment and acceptance towards the customs and ideas that represent shared group experiences and a collective fate (Schwartz, 1992). These experiences and fate symbolise a group's unique and enduring ethos, promoting its solidarity and survival (Durkheim, 1912; Parsons, 1951; Schwartz, 1992; Halperin \& Bar-Tal, 2011).

This study posits that traditionalism is positively related to hostile intent attribution. Traditionalism may lead to cognition that is based on categorising, thereby providing a basis for a negative attitude held towards out-groups. Indeed, empirical studies have shown that traditionalism can induce detrimental effects such as a positive association with anti-immigrant behaviour (Schwartz, 2009), foreign military intervention (Schwartz, 2010) and authoritarianism (Schwartz, 2003). An overemphasis on tradition may also result in feelings of unease, oppression and sensitivity pertaining to anything that could lead to changes in the group among in-group members. These manifestations of anxiety may, in turn, promote a high level of traditionalism that results in avoidance of intergroup contact and induces attribution of negative traits to out-groups to justify this behaviour. The greater the degree of importance attached by people to the preservation of their own culture, the greater the likelihood that they will show heightened sensitivity towards anything that could harm their group (González, Verkuyten, Weesie, \& Poppe, 2008). Furthermore, because traditionalism generates positive feelings towards the in-group, in an ambiguous situation requiring self-protection, it provides a basis for attributing wrongdoing to an out-group. Thus, we postulate in this study that traditionalism is likely to promote a perception of hostility attributed to out-groups and aimed at maintaining an in-group's sense of unique features rooted in the past. 


\subsubsection{Universalism}

Universalism has been defined as the motivation to understand, appreciate and tolerate different or even rival groups and to promote the welfare of all people by emphasising broadmindedness, social justice, equality, a peaceful and beautiful world, unity with nature and environmental protection (Schwartz, 1992). Universalism holds that there are no differences between people across the world and that everyone must be treated equally.

In our study, we posited that universalism has a positive effect on hostile intent attribution. Universalism is more likely to evoke positive perceptions and prosocial activity that benefit the world (Schwartz, 2007). It even motivates actions of self-sacrifice to promote the welfare of others (Schwartz, 2009). Indeed, several empirical studies have shown that universalism is a contributing factor in promoting a positive attitude towards out-groups (Halperin \& Bar-Tal, 2011; Sagiv \& Schwartz, 1995) and a tendency to accept out-groups (Schwartz, 2009). Contrasting with traditionalism, universalism does not induce anxiety over anything transformative and, therefore, advances the development of positive intragroup interactions. Furthermore, because universalism incorporates self-sacrifice as a characteristic feature, it is less likely to result in hostile intent being attributed to others to justify the behaviour of in-group members, even in ambiguous situations. Thus, it may be an important factor in decreasing hostile intent attribution.

\subsection{Perceived Threats as Mediators}

Our study, which is based on integrated threat theory propounded by Stephen and Stephen (1996), incorporates several theoretical perspectives on intergroup attitudes. Integrated threat theory identifies four main types of threats: realistic threats, symbolic threats, intergroup anxiety and negative stereotypes (Stephan \& Stephan, 1996). Although all four threat types contribute to negative attitudes held towards out-groups, this study focuses mainly on perceived realistic and symbolic threats, because these are the most typical threat types evident in negative intergroup relations (Bobo, 1983; Esses, Jackson, \& Armstrong, 1998; Falomir-Pichastor, Muñoz-Rojas, Invernizzi, \& Mugny, 2004).

The conception of realistic threats, which originates in realistic group conflict theory, has been further expanded by Stephan, Stephan and Gudykunst (1999). In line with this expanded conception, a realistic threat, as applied in this study, refers to the subjective perception held by an in-group that its welfare is threatened by out-groups, regardless of whether or not the threat is "real". We specifically focus on realistic threats emanating from market competition and from security, political power and material considerations.

Within integrated threat theory, symbolic threats relate to conflicts of value that can also have detrimental effects on intergroup relations (Riek, Mania, \& Gaertner, 2006). The conception of symbolic threats is derived from symbolic racism which entails the desire to protect certain cultural symbols and arouses negative individual attitudes towards out-groups (McLaren, 2003). In accordance with symbolic racism theory, symbolic threats, as applied in our study, refer to the subjective perception that the in-group's existing value system and culture are being threatened by out-groups.

We hypothesised that perceived threats may play an important role in mediating relations between traditionalism and hostile intent attribution for two reasons. First, traditionalism entails the following conservative characteristics: resistance to change (Schwartz, 2006a), a desire to preserve habits and customs and belief in an immutable past (Schwartz, 2009). These characteristics of traditionalism serve to sensitise in-group members, desiring to protect or maintain the group's traditions, to anything that may affect their customs and ideas. Interactions with out-groups that have even slightly different cultures and values may affect the integrity of symbols, ideas and beliefs within the in-group, causing strongly traditionalistic members to feel easily threatened. Similarly, nationalism, which advocates the importance of maintaining cultural values, has been associated with perceived threats (Ljujic, Vedder, Dekker, \& Geel, 2013). Second, several empirical studies have shown that perceptions of symbolic and realistic threats play important underlying roles in fostering prejudice against out-groups (Riek et al., 2006, Curseu, Stoop, \& Schalk, 2007; Ljujic et al., 2013). Perceived threats readily induce psychological distress. Previous studies have shown that the perception that the in-group is under threat easily leads to negative feelings held by its members towards an out-group. This includes characterisation of the out-group as being violent and intrusive (González et al., 2008; Sniderman, Hagendoorn, \& Prior, 2004). Thus, when group members encounter a situation in which out-groups deprive them of their resources, security or values, or destroy these, they are likely to consider these groups as competitors with hostile intent towards their own group.

We also suggest that perceived threats play a mediating role between universalism and hostile intent attribution for the following reason. As previously mentioned, those who uphold universalism easily accept others who differ from them (Schwartz, 2009), have positive perceptions of out-groups and promote prosocial activities that 
benefit the world (Schwartz, 2010). Studies have found that an attitude entailing a high level of acceptance towards others is associated with a correspondingly low level of perceived threats (González et al., 2008). It leads to fewer threats being perceived and a more positive attitude towards out-groups compared with an attitude that entails a low level of acceptance towards others (Rohmann, Florack, \& Piontkowski, 2006; Ljujic et al., 2013). Based on these findings, it is reasonable for us to argue that universalism is associated with fewer perceived threats compared with traditionalism. As such, we expect that universalism directly influences perceived threats, and, further, that it affects hostile intent attribution through the mediation of perceived threats.

Although traditionalism and universalism often entail totally different attitudes towards out-groups, this does not imply a conflictual relationship between them. We suggest that they can mutually coexist within people's value systems. Traditionalists may also uphold universalistic values. For example, pursuing environmental protection can simultaneously preserve traditional customs. The difference between these two values is that whereas traditionalism entails devotion to the in-group, universalism is concerned with others and not with self-interest (Schwartz, 2006b). We suggest that these different value characteristics are the root cause of differences in perceptions held towards out-groups.

Based on the above statements, we propose the following hypotheses:

Hypothesis 1: Perceived threats mediate a positive relationship between traditionalism and hostile intent attribution.

Hypothesis 2: Perceived threats mediate a negative relationship between universalism and hostile intent attribution.

Hypothesis 3: Hostile intent attribution will predict support for aggressive policies.

\section{Method}

\subsection{Participants}

To test our hypotheses, we conducted a questionnaire-based survey of population samples belonging to two different cultural contexts. We gathered data from 201 Chinese undergraduate students and from 256 Japanese undergraduate students in June 2013. The participants were asked to complete the questionnaire during regular school hours. The questionnaire took approximately 15 minutes to complete.

Chinese participants, with a mean age of 19.8 years $(S D=1.26)$, consisted of 63 males, 134 females and 4 participants who did not report their sex. The participants were from three universities located in Sichuan Province, and their legal domiciles covered almost every Chinese province. We distributed and collected questionnaires with the assistance of instructors employed at these universities.

Japanese participants, with a mean age of 19.19 years $(S D=1.41)$, consisted of 113 males, 142 females and 1 participant whose sex was unreported. The participants were from two universities located in Fukuoka Prefecture and were legally domiciled in various Japanese prefectures. We also distributed and collected questionnaires with the assistance of instructors employed at these universities.

\subsection{Measures}

The questionnaire used for the survey included demographic questions as well as measures of traditionalism, universalism, realistic threat, symbolic threat and hostile intent attribution. Questionnaire items were originally written in Japanese and then translated into Chinese. We applied a back-translation procedure to check that meanings were comparable. All of the questionnaire items were rated on a five-point scale ranging from (1) strongly disagree to (5) strongly agree.

Symbolic threat was assessed with four items that focused on perceptions that an out-group was threatening the in-group's values and culture. While the items were based on the work of Stephen, Martnez, Schwarzwald and Tur-Kaspa (1998), we modified them to suit the present study. Two examples of these items were: "Chinese values are being threatened by Japan" and "Chinese and Japanese values are mutually exclusive". Values for Cronbach's $\alpha$ for the Chinese and Japanese samples were .81 and .76, respectively.

Realistic threat was measured with four items relating to security, the market, political statutes and dominion. These items were also derived from Stephen et al. (1998) and modified for the present study. Examples included: "The Chinese (or Japanese) market is now threatened by Japan (China)" and "Japan has threatened Chinese social security". These scales proved reliable, and values for Cronbach's $\alpha$ for the Chinese and Japanese samples were .79 and .61 , respectively.

Traditionalism was measured with four items adapted from Schwartz (2003). These items described an 
individual's beliefs. Examples included: "I think I should not ask for more than what I have"; "I believe that people should be satisfied with what they have"; "I believe it is better to do things in traditional ways"; and "It is important to follow the customs one has learned". Values for Cronbach's $\alpha$ for the Chinese and Japanese samples were .72 and .66 , respectively.

Universalism was measured with six items that focused on equality, world peace, justice and environmental protection. Examples were: "I think it is important that every person in the world should be treated equally"; "I think justice is necessary for everybody, even for people I don't know"; and "It is important for me to adapt to nature and to fit into it. I believe that people should not change nature". The response scales were also adapted from Schwartz (2003). Values for Cronbach's $\alpha$ for the Chinese and Japanese samples were .89 and .77, respectively.

Hostile intent attribution was assessed with two items that focused on the perception that an out-group intended to harm the in-group. The items described the strength of the perceived intention to harm within the Chinese and Japanese samples. Examples included: "Japanese always embarrass Chinese on purpose and the behaviours of the Japanese reflect malicious intentions towards China". The value of Cronbach's $\alpha$ for both the Chinese and Japanese samples was .87.

Support for aggressive policies was measured with three items derived from research on Japan-China relations (Nawata \& Yamaguchi, 2012). The items described the strength of perceived victimhood within the Chinese and Japanese samples. An example was: "If Japan has aggressive intentions toward China, we should consider pre-emptive action". Values for Cronbach's $\alpha$ for the Chinese and Japanese samples were .63 and .80 , respectively.

After completing the questionnaire, participants were asked to fill out their age, sex and nationality details. They could subsequently share their opinions freely with us.

\section{Results}

Table 1. Means and standard deviations of measured variables for the Chinese and Japanese samples

\begin{tabular}{lcccc}
\hline \multirow{2}{*}{ Variable } & \multicolumn{2}{c}{ Chinese $(N=202)$} & \multicolumn{2}{c}{ Japanese $(N=256)$} \\
\cline { 2 - 5 } & $\mathrm{M}$ & $\mathrm{SD}$ & $\mathrm{M}$ & $\mathrm{SD}$ \\
\hline Traditionalism & 3.41 & .80 & 3.03 & .70 \\
Universalism & 4.06 & .84 & 4.05 & .63 \\
Symbolic threat & 2.26 & .94 & 2.28 & .84 \\
Realistic threat & 2.44 & .95 & 3.03 & .76 \\
Hostile intent attribution & 3.28 & 1.08 & 2.88 & 1.14 \\
Support for aggressive & 4.24 & .78 & 2.74 & 1.01 \\
policies & & & & \\
\hline
\end{tabular}

Although correlations between some of the variables were not strong in the Chinese sample (for example, $r=.14$ and $p<.10$ for traditionalism and realistic threat), almost all of our expected relations were significantly correlated. The uncorrelated relation between universalism and realistic threat in the Japanese sample was exceptional. The results of the intercorrelations are shown in Table 2.

Table 2. Intercorrelations between measured variables for the Chinese and Japanese samples

\begin{tabular}{lcccccc}
\hline & 1 & 2 & 3 & 4 & 5 & 6 \\
\hline 1. Traditionalism & - & $.35^{* *}$ & $.17^{*}$ & $.14^{\dagger}$ & $.25^{* *}$ & $.13^{\dagger}$ \\
2. Universalism & $.23^{* *}$ & - & $-.17^{*}$ & $-.16^{* *}$ & -.01 & .08 \\
3. Symbolic threat & $.22^{* *}$ & $-.14^{*}$ & $-54^{* *}$ & $.65^{* *}$ & $.34^{* *}$ & $.13^{\dagger}$ \\
4. Realistic threat & $.17^{* *}$ & -.01 & $.50^{* *}$ & $-38^{* *}$ & $.31^{* *}$ & $.06^{* *}$ \\
5. Hostile intent attribution & $.11^{\dagger}$ & -.04 & $.57^{* *}$ & $.31^{* *}$ & - & $.41^{* *}$ \\
$\begin{array}{l}\text { 6. Support for aggressive } \\
\text { policies }\end{array}$ & $.24^{* *}$ & -.06 & $.40^{* *}$ & $.34^{* *}$ & $.38^{*}$ & -
\end{tabular}

Note. Correlations were above the diagonal for the Chinese sample and below the diagonal for the Japanese sample. ${ }^{* *} p<.01 ;{ }^{*} p<.05 ;{ }^{\dagger} p<.10$.

To test our model and examine its compatibility, we conducted structural equation modelling using the Amos 
program in the SPSS 17.0 package. We also conducted a multi-group path analysis to compare implementation of the same model for the Chinese and Japanese samples. We tested our hypothesis that symbolic and realistic threats fully mediate the relationship between antecedents (traditionalism and universalism) and hostile intent attribution. The modified model and the relationship between the variables are presented in Figure 1 which shows that there was a good fit between the model and the data $\left(\chi^{2}=39.74, d f=12, p<.001\right.$, GFI $=.97$, AGFI $=.90, \mathrm{NFI}=.92, \mathrm{CFI}=.94, \mathrm{RMSEA}=.07)$. We can explain the relationship between the variables based on the proposed model.

Figure 1 shows that for both the Chinese and Japanese samples, traditionalism had a positive relation with symbolic threat $(\beta=.26, p<.001 ; \beta=.27, p<.001$, respectively) as well as with realistic threat $(\beta=.22, p<.01$; $\beta=.19, p<.01$, respectively). Conversely, universalism was negatively associated with both symbolic threat ( $\beta$ $=-.27, p<.001 ; \beta=-.20, p<.01$, respectively), and realistic threat $(\beta=-.24, p<.01 ; \beta=-.05$, n.s. respectively) for these two samples. Symbolic threat was positively associated with hostile intent attribution in both the Chinese and Japanese samples $(\beta=.34, p<.001 ; \beta=.45, p<.001$, respectively). Realistic threat was positively associated with hostile intent attribution in the Japanese sample $(\beta=.13, p<.05)$, but not in the Chinese sample $(\beta=.15, p<.10)$. Traditionalism and universalism both showed a significant positive correlation $(r=.35, p<.001 ; r=.23, p<.001$, respectively) in the Chinese and Japanese samples. Furthermore, a positive correlation was found between symbolic and realistic threats $(r=.62, p<.001 ; r=.48, p<.001$, respectively) for the two samples. Multi-group path analysis was thus a useful method for comparing paths in different models. An absolute value greater than 1.96 suggested a significant difference at $p<.05$. Comparison of the results of the two models showed that the symbolic threat path predicted hostile intent attribution is difference. The path's absolute value was 3.19.

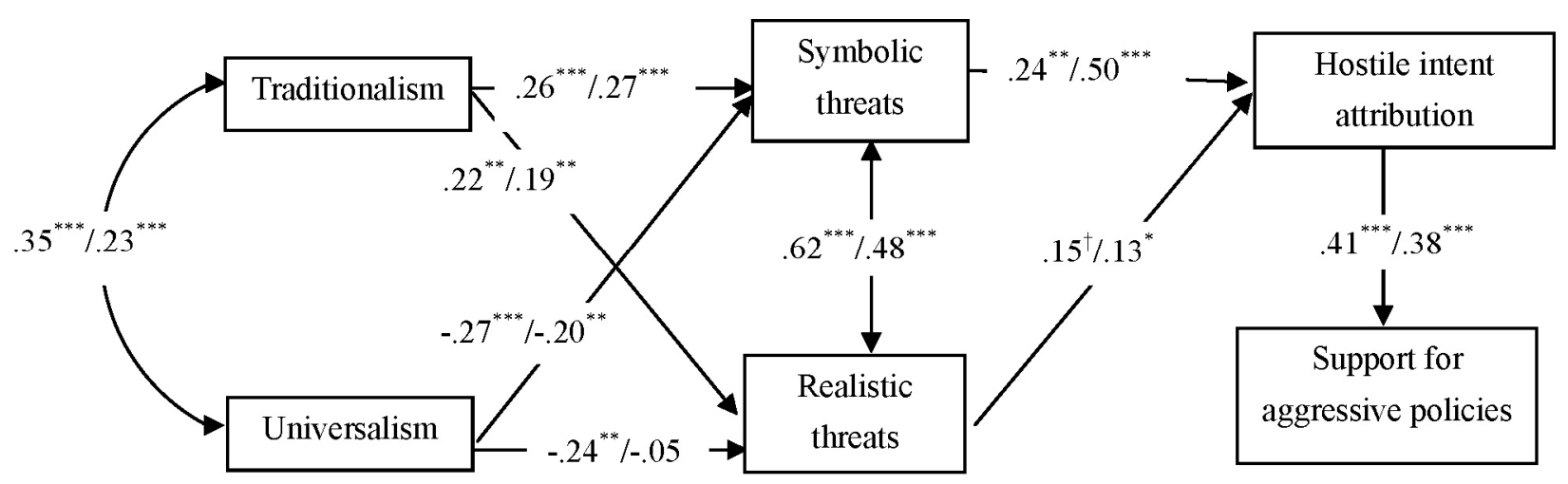

Figure 1. Multi-Group path analysis for the Chinese and Japanese samples

Note. The left and right standardised paths relate to the Chinese and Japanese samples, respectively.

${ }^{* * *} p<.001 ;{ }^{* *} p<.01 ;{ }^{*} p<.05 ;{ }^{*} p<.10$.

To test mediation effects, we conducted a series of Sobel tests (Baron \& Kenny, 1986). As shown in Table 3, the mediation effect of symbolic threats in the relationship between traditionalism and hostile intent attribution $(\mathrm{z}=$ $2.19, p<.05 ; \mathrm{z}=3.87, p<.001)$, as well as in the relationship between universalism and hostile intent attribution $(\mathrm{z}=-2.22, p<.05 ; \mathrm{z}=-3.30, p<.001)$, was evident for the Chinese and Japanese samples, respectively. However, realistic threats were neither found to mediate the relationship between traditionalism and hostile intent attribution $(\mathrm{z}=1.54, p=.12 ; \mathrm{z}=1.72, p=.09)$ nor the relationship between universalism and hostile intent attribution $(\mathrm{z}=-1.57, p=.08 ; \mathrm{z}=-0.75, p=.45)$ in the Chinese and Japanese samples, respectively.

Table 3. Sobel tests for mediated relations

\begin{tabular}{ccccccc}
\hline Predictor & Mediator & Criterion & $\begin{array}{c}\text { Chinese } \\
\text { z-test }\end{array}$ & $\begin{array}{c}\text { Chinese } \\
\text { p-value }\end{array}$ & $\begin{array}{c}\text { Japanese } \\
\text { z-test }\end{array}$ & $\begin{array}{c}\text { Japanese } \\
\text { p-value }\end{array}$ \\
\hline Traditionalism & Symbolic threat & $\begin{array}{c}\text { Hostile intent } \\
\text { attribution }\end{array}$ & 2.19 & $.03^{*}$ & 3.87 & $.001^{* * *}$
\end{tabular}




$\begin{array}{ccccccc}\text { Universalism } & \text { Symbolic threat } & \begin{array}{c}\text { Hostile intent } \\ \text { attribution }\end{array} & -2.22 & .03^{*} & -3.30 & .001^{* * *} \\ \text { Traditionalism } & \text { Realistic threat } & \begin{array}{c}\text { Hostile intent } \\ \text { attribution }\end{array} & 1.54 & .12 & 1.72 & .09^{\dagger} \\ \text { Universalism } & \text { Realistic threat } & \begin{array}{c}\text { Hostile intent } \\ \text { attribution }\end{array} & -1.57 & .08 & -.75 & .45\end{array}$

Note. ${ }^{* * *} p<.001 ;{ }^{* *} p<.01 ;{ }^{*} p<.05 ;{ }^{\dagger} p<.10$.

\subsection{Alternative Models}

Although the proposed model fitted the data well, we proposed five alternative models to confirm its suitability by changing the positions of antecedent, mediator and criterion variables. In the first alternative model, in which the mediators were perceived threat and support for aggressive policies and hostile intent attribution was the criterion variable, the fit was not $\operatorname{good}\left(\chi^{2}=115.92, d f=12, p<.001, \mathrm{GFI}=.93, \mathrm{AGFI}=.75, \mathrm{NFI}=.78, \mathrm{CFI}\right.$ $=.79$, RMSEA $=.14)$. The fit was also not good for the second alternative model, in which values and support for aggressive policies were the mediators, perceived threat was the antecedent and hostile intent attribution was the criterion variable $\left(\chi^{2}=148.05, d f=12, p<.001, \mathrm{GFI}=.92, \mathrm{AGFI}=.71, \mathrm{NFI}=.71, \mathrm{CFI}=.72\right.$, RMSEA $=.16$ ). For the third alternative model in which values and hostile intent attribution were the mediators, perceived threat was the antecedent and support for aggressive policies was the criterion variable, the fit was similarly not good $\left(\chi^{2}=186.198, d f=16, p<.001, \mathrm{GFI}=.90, \mathrm{AGFI}=.73, \mathrm{NFI}=.64, \mathrm{CFI}=.65, \mathrm{RMSEA}=.15\right)$. For the fourth alternative model, values and hostile intent attribution were the mediators, with hostile intent attribution mediating between perceived threat and values, while perceived threat was the antecedent and support for aggressive policies was the criterion variable. Here too, the fit was not $\operatorname{good}\left(\chi^{2}=164.66, d f=16, p<.001\right.$, $\mathrm{GFI}=.91, \mathrm{AGFI}=.75, \mathrm{NFI}=.68, \mathrm{CFI}=.69, \mathrm{RMSEA}=.14)$. For the fifth and final alternative model in which values and hostile intent attribution were the mediators, perceived threat was the antecedent and support for aggressive policies was the criterion variable, the fit was not good $\left(\chi^{2}=186.198, d f=16, p<.001\right.$, GFI $=.90$, $\mathrm{AGFI}=.73, \mathrm{NFI}=.64, \mathrm{CFI}=.65, \mathrm{RMSEA}=.15)$. Thus, we considered the model shown in Figure 1 to be the best fit compared with these other alternatives.

\section{Discussion}

The primary purpose of this study was to examine the relationship between the values of traditionalism and universalism and hostile intent attribution. Furthermore, it aimed to confirm the role of perceived threats as mediators of the relationship between traditionalism, universalism and hostile intent attribution, as well as verify that hostile intent attribution predicts support for aggressive policies. The results of this study were generally in line with our predictions. First, symbolic threat mediated the relationship between traditionalism and hostile intent attribution. However, universalism reduced perceptions of symbolic threat within both the Chinese and Japanese samples. However, we did not find a mediated effect for realistic threats within the two samples. In partial accordance with our prediction, universalism predicted realistic threat for the Chinese sample, but not for the Japanese one. Hypotheses 1 and 2 were thus partially supported. Second, hostile intent attribution predicted support for aggressive policies within both samples.

\subsection{Findings}

The first key finding of the study was that the value of traditionalism appeared to be a predictor of hostile intent attribution via symbolic threats within both the Chinese and Japanese samples. Traditionalism entails a conservative motivation (Schwartz, 2012) that makes it difficult for people to accept out-groups (Sagiv \& Schwartz, 1995). These results suggest that a higher level of traditionalism entails a greater responsibility to protect the original in-group culture. People with this sense of mission will be constantly vigilant against out-groups who may bring in change. In a confrontation between countries with different cultural contexts, traditionalism may reflect greater anxiety or the fear that each country will destroy the national value system and well-being of the other. Therefore, a high degree of traditionalism leads to a high level of perceived threats. Perceived threats seem to capture the perception of hostility and serve as important mediating variables in the association between traditionalism and hostile intent attribution. This study's findings suggest that traditionalism is a key factor underlying negative intergroup relationships.

Second, universalism predicted hostile intent attribution through symbolic threats in both samples. It also predicted realistic threats within the Chinese sample. These results imply that universalism could reduce a sense 
of hostility by weakening perceived threats, particularly symbolic threats. Universalism encourages acceptance of out-groups and even the possibility of individuals or groups sacrificing their own interests for the sake of others (Schwartz, 2007, 2010). In contrast to traditionalism, strong universalism is likely to promote positive intergroup relationships. Our investigation provided evidence that supports this viewpoint. This is an important finding that can help to establish positive intergroup relations when a desire to repair these relations exists.

Third, in both samples symbolic threats mediated the impacts of traditionalism and universalism on hostile intent attribution. However, realistic threats did not evidence a mediating effect in either of the samples. According to the intergroup context, different types of threats have differential impacts on prejudice held towards out-groups (Stephen \& Stephen, 1996). In fact, many empirical studies have endorsed this view. For example, in the context of the Netherlands, González et al. (2008) found that prejudice was associated with symbolic threats, but not with realistic threats. By contrast, in the Israeli context, Bizman and Yinon (2001) found that realistic but not symbolic threats predicted prejudice. The findings of the current study, in the context of China and Japan, are that symbolic threats are more significantly associated with hostile intent attribution compared with realistic threats. The reason for this may be that each of these societies, viewing the other as an out-group, perceives differences in values and culture, rather than physical intimidation, as threatening. Consequently, they are more inclined to readily characterise the out-group as being hostile towards the in-group. Thus, for the Chinese and Japanese people, the perception of threat posed by different values and beliefs may increase the negative feelings they hold towards each other as out-groups. Furthermore, as the results show, symbolic threats are more significantly associated with hostile intent attribution in the Japanese context compared with the Chinese context. Thus, in the context of Japan and China, our study has produced evidence in support of the viewpoint that different types of threats lead to differential prejudice towards out-groups. It has also demonstrated that the same type of threat predicts different levels of reflection towards out-groups.

Last, the results indicate that hostile intent attribution predicted support for aggressive polices within both samples. As discussed in the earlier section on theory, hostile intent attribution has been associated with aggressive behaviour (Matthews \& Norris, 2002; Tremblay \& Belchevski, 2004). However, empirical studies investigating the relationship between hostile intent attribution and aggressive behaviour in the intergroup context remain limited. As indicated by our results, hostile intent attribution significantly explains support for aggressive policies towards out-groups. Our study thus contributes to the literature by demonstrating that hostile intent attribution is an explanatory factor in relation to intergroup conflict.

\subsection{Theoretical Implications}

The findings of this comparative study have some important theoretical implications. First, to the best of our knowledge, our study is the first to examine the relationship between basic human values and perceived threats. It demonstrates that values can promote and, conversely, reduce a particular intergroup attitude. This finding helps to extend the literature on intergroup relationships from a new perspective. Second, we applied integrated threat theory to propose a detailed psychological process. Our study indicates that perceived threat is an important explanatory mechanism in the relationship between the values of traditionalism and universalism and hostile intent attribution. Our study is the first to examine the sequential mediating effects of values and hostile intent attribution. It, therefore, advances understanding of why traditionalism predicts negative attitudes towards out-groups, while universalism predicts positive attitudes towards them. Third, as the samples in this study were from China and Japan, these findings can deepen our understanding of conflicts between these countries. By applying the theory of perceived threats in our study, we were able to explain some aspects of the relationship between China and Japan. We discuss these in detail below.

\subsection{Practical Implications}

The practical implications of our findings for enhancing understanding of the China-Japan relationship are as follows. First, the results indicate that traditionalism tended to predict perceived threats within both the Chinese and Japanese samples, while universalism had the potential to improve this intergroup relationship. These two contrasting value types can, however, coexist within human value systems. Thus, we suggest that in combination with retention of traditional beliefs or ideas, it is important to strengthen universalism by expanding consciousness of human welfare, or of the natural environment. Our findings further suggest that hostile intent attribution predicts support for aggressive policies as an important psychological process and, ultimately, a deteriorating relationship between China and Japan. Cultural exchange should, therefore, be promoted to increase mutual understanding and reduce the perception of hostile intent.

\subsection{Limitations and Directions for Future Research}

This study has three major limitations. First, like other correlational studies, it could not provide definitive 
conclusions regarding causation between the variables. It is difficult to ascertain whether perceived threats predict traditionalism, or whether perceived threats precede hostile intent attribution. Thus, it is necessary for a future experimental design to provide this evidence. Second, we only obtained samples from China and Japan. Further exploration is, therefore, needed on whether our proposed model can be applied more generally to the psychological processes of other nations. We recommend obtaining samples of cross-cultural participants within future studies to examine the generalisability of this model. Third, the present study focused on relationships among values (traditionalism/universalism), perceived threats (realistic/symbolic), hostile intent attribution and support for aggressive policies. However, extended research is required to test other types of values, such as benevolence and conformity, and other types of threats, such as stereotypes, as well as their relationships to perceived threats.

\section{References}

Baron, R. M., \& Kenny, D. A. (1986). The moderator-mediator variable distinction in social psychological research: Conceptual, strategic, and statistical considerations. Journal of Personality and Social Psychology, 51, 1173-1182. http://dx.doi.org/10.1037/0022-3514.51.6.1173

Bizman, A., \& Yinon, Y. (2001). Intergroup and interpersonal threats as determinants of prejudice: The moderating role of in-group identification. Basic and Applied Social Psychology, 23, 191-196. http://dx.doi.org/10.1207/S15324834BASP2303_5

Bobo, L. (1983). Whites' opposition to busing: Symbolic racism or realistic group conflict? Journal of Personality and Social Psychology, 45, 1196-1210. http://dx.doi.org/10.1037/0022-3514.45.6.1196

Curseu, P. L., Stoop, R., \& Schalk, R. (2007). Prejudice toward immigrant workers among Dutch employees: Integrated threats theory revisited. European Journal of Social Psychology, 37, 125-140. http://dx.doi.org/10.1002/ejsp.331

Dean, J. M., Lovely, M. E., \& Mora, J. (2009). Decomposing China-Japan-U.S. trade: Vertical specialization, ownership, and organizational form. Paper presented at the Conference on China, Japan, and United States: Deeper integration, Tokyo, Japan.

Dill, K. E., Anderson, C. A., \& Deuser, W. E. (1997). Effects of aggressive personality on social expectations and social perceptions. Journal of Research in Personality, 31, 272-292. http://dx.doi.org/10.1006/jrpe.1997.2183

Durkheim, E. (1912). The elementary forms of religious life. New York, NY: Free Press.

Esses, V. M., Jackson, L. M., \& Armstrong, T. L. (1998). Intergroup competition and attitudes toward immigrants and immigration: An instrumental model of group conflict. Journal of Social Issues, 54, 699-724. http://dx.doi.org/10.1111/j.1540-4560.1998.tb01244.x

Falomir-Pichastor, J. M., Muñoz-Rojas, D., Invernizzi, F., \& Mugny, G. (2004). Perceived in-group threats as a factor moderating the influence of in-group norms on discrimination against foreigners. European Journal of Social Psychology, 34, 135-153. http://dx.doi.org/10.1002/ejsp.189

González, K. V., Verkuyten, M., Weesie, J., \& Poppe, E. (2008). Prejudice towards Muslims in the Netherlands: Testing integrated threat theory. British Journal of Social Psychology, 47, 667-685. http://dx.doi.org/10.1348/014466608X284443

Halperin, E., \& Bar-Tal, D. (2011). Socio-psychological barriers to peace making: An empirical examination within the Israeli Jewish society. Journal of Peace Research, 48, 637-651. http://dx.doi.org/10.1177/0022343311412642

He, Y. (2007). History, Chinese nationalism and the emerging Sino-Japanese conflict. Journal of Contemporary China, 16, 1-24. http://dx.doi.org/10.1080/10670560601026710

Koh, Y. (2012). Love Thy Neighbor? How China and Japan see each other. The Wall Street Journal. Retrieved July 21, 2013, from http://blogs.wsj.com/japanrealtime/2012/06/21/love-thy-neighbor-how-china-and -japan-see-each-other

Ljujic, V., Vedder, P., Dekker, H., \& Geel, M. (2013). Romaphobia among Serbian and Dutch adolescents: The role of perceived threats, nationalistic feelings, and integrative orientations. International Journal of Psychology, 48, 352-362. http://dx.doi.org/10.1080/00207594.2012.661060

Matthews, B. A., \& Norris, F. H. (2002). When is believing "seeing"? Hostile attribution bias as a function of self-reported aggression. Journal of Applied Social Psychology, 32, 1-32. 
http://dx.doi.org/10.1111/j.1559-1816.2002.tb01418.x

McLaren, L. M. (2003). Anti-immigrant prejudice in Europe: Contact, threats perception, and preferences for the exclusion of migrants. Social Forces, 81, 909-936. http://dx.doi.org/10.1353/sof.2003.0038

Milich, R., \& Dodge, K. A. (1984). Social information processing in child psychiatric populations. Journal of Abnormal Child Psychology, 12, 471-490. http://dx.doi.org/10.1007/BF00910660

Nawata, K., \& Yamaguchi, H. (2012). The role of collective victimhood in intergroup aggression: Japan-China relations. Shinrigaku Kenkyu: The Japanese Journal of Psychology, 83, 489-495. http://dx.doi.org/10.4992/jjpsy.83.489

Nishimura, Y., \& Hirayama, K. (2013). Does exchange rate volatility deter Japan-China trade? Evidence from pre- and post-exchange rate reform in China. Japan and the World Economy, 25-26, 90-101. http://dx.doi.org/10.1016/j.japwor.2013.03.002

Nye, J. S. (2013). Our Pacific predicament. The American Interest, 8(4). Retrieved March 13, 2013, from http://www.the-american-interest.com/2013/02/12/our-pacific- predicament/

Parsons, T. (1951). The social system. New York, NY: Free Press.

Qiu, J. (2006). The politics of history and historical memory in China-Japan relations. Journal of Chinese Political Science, 11, 25-53. http://dx.doi.org/10.1007/BF02877032

Riek, B. M., Mania, E. W., \& Gaertner, S. L. (2006). Intergroup threats and outgroup attitude: A meta-analytic review. Personality and Social Psychology Review, 10, 336-353. http://dx.doi.org/10.1207/s15327957pspr1004_4

Rohmann, A., Florack, A., \& Piontkowski, U. (2006). The role of acculturation attitudes in perceived threat: An analysis of host and immigrant attitudes in Germany. International Journal of Intercultural Relations, 30, 683-702. http://dx.doi.org/10.1016/j.ijintrel.2006.06.006

Sagiv, L., \& Schwartz, S. H. (1995). Value priorities and readiness for out-group social contact. Journal of Personality and Social Psychology, 69, 437-448. http://dx.doi.org/10.1037/0022-3514.69.3.437

Schwartz, S. H. (1992). Universals in the content and structure of values: Theoretical advances and empirical tests in 20 countries. In M. Zanna (Ed.), Advances in experimental social psychology (pp. 1-65). New York, NY: Academic Press.

Schwartz, S. H. (2003). A proposal for measuring value orientations across nations. Chapter 7 in The Questionnaire Development Report of the European Social Survey. Retrieved September 20, 2011, from http://www.europeansocialsurvey.org/index.php?option=com_docman\&gid=126\&itemid=80

Schwartz, S. H. (2006a). Basic human values: An overview. Retrieved September 20, 2011, from http://151.97.110.134/ Allegati/convegno\%207-8-10-05/Schwartzpaper.pdf

Schwartz, S. H. (2006b). Les valeurs de base de la personne: Théorie, mesures et applications [Basic human values: Theory, measurement, and applications]. Revue Française de Sociologie, 47, 249-288. http://dx.doi.org/10.3917/rfs.474.0929

Schwartz, S. H. (2007). Universalism values and the inclusiveness of our moral universe. Journal of Cross-Cultural Psychology, 38, 711-728. http://dx.doi.org/10.1177/0022022107308992

Schwartz, S. H. (2009). Basic human values. Retrieved September 20, 2011, from http://ccsr.ac.uk/qmss/seminars/2009-06-10/documents/Shalom_Schwartz_1.pdf

Schwartz, S. H. (2010). Basic personal values, core political values, and voting: A longitudinal analysis. Political Psychology, 31, 342-421. http://dx.doi.org/10.1111/j.1467-9221.2010.00764.x

Schwartz, S. H. (2012). An overview of the Schwartz theory of basic values. Online Readings in Psychology and Culture, 2(1), 1-20. http//dx.doi.org/10.9707/2307-0919.1116

Sniderman, P. M., Hagendoorn, L., \& Prior, M. (2004). Predisposing factors and situational triggers: Exclusionary reactions to immigrant minorities. American Political Science Review, 98, 35-49. http://dx.doi.org/10.1017/S000305540400098X

Spector, P. E., \& Fox, S. (2010). Theorizing about the deviant citizen: An attributional explanation of the interplay of organizational citizenship and counterproductive work behaviour. Human Resource Management Review, 20, 132-143. http://dx.doi.org/10.1016/j.hrmr.2009.06.002 
Stephan, W. G., \& Stephan, C. W. (1996). Predicting prejudice. International Journal of Intercultural Relations, 20, 409-426. http://dx.doi.org/10.1016/0147-1767(96)00026-0

Stephan, W. G., Stephan, C. W., \& Gudykunst, W. B. (1999). Anxiety in intergroup relations: A comparison of anxiety/uncertainty management theory and integrated threat theory. International Journal of Intercultural Relations, 23, 613-628. http://dx.doi.org/10.1016/S0147-1767(99)00012-7

Stephan, W. G., Ybarra, O., Martnez, C., Schwarzwald, J., \& Tur-Kaspa, M. (1998). Prejudice toward immigrants to Spain and Israel: Integrated threat theory analysis. Journal of Cross-Cultural Psychology, 29, 559-576. http://dx.doi.org/10.1177/0022022198294004

The Genron NPO. (2012). Non-profit organization. Retrieved December 12, 2012, from http://www.genron-npo.net/press /2012 / 06/npo-10.html

Tremblay, P. F., \& Belchevski, M. (2004). Did the instigator intend to provoke? A key moderator in the relation between trait aggression and aggressive behaviour. Aggressive Behaviour, 30, 409-424. http://dx.doi.org/10.1002/ab.20027

\section{Copyrights}

Copyright for this article is retained by the author(s), with first publication rights granted to the journal.

This is an open-access article distributed under the terms and conditions of the Creative Commons Attribution license (http://creativecommons.org/licenses/by/3.0/). 